\title{
La narratividad crítica de la revista Barcelona ${ }^{1}$
}

\author{
The narrative critique of the magazine Barcelona
}

\author{
Mgter. Phellipy JÁCOME \\ Universidade Federal de Minas Gerais (Brasil) \\ phellipy@ufmg.br
}

Recibido: 10 de septiembre 2013

Aceptado y Publicado: 8 de noviembre de 2013

\section{Resumen}

Describir lo real sin perturbarlo y fijarlo como verdad objetiva tal vez sea la gran quimera del periodismo. La creencia y la búsqueda de objetividad y fidelidad a los "hechos" son elementos fundadores de una retórica periodística que marca, a través de esos criterios, las barreras entre un periodismo serio y empeñado y otros, desviantes y descomprometidos. Desde esta perspectiva, el periodismo necesita vincularse estrechamente a normas de veracidad que sirven, sobre todo, para regular y legitimar aquello que es producido y ofertado.

\section{Abstract}

Describe without disturbing reality and set it as objective truth is perhaps the great chimera of journalism. The belief and the search for objectivity and loyalty to the "facts" are founding elements of journalistic rhetoric brand through these criteria, the barriers between serious journalism and others bent, deviant and disengaged. From this perspective, journalism needs

\footnotetext{
${ }^{1}$ Artículo producto de una Ponencia presentada en el VI Encuentro Panamericano de Comunicación COM PANAM 2013 celebrado la Escuela de Ciencias de la Información de la Universidad Nacional de Córdoba (Argentina), durante los días 5, 6 y 7 de junio de 2013.
} 
to be linked closely to standards of truthfulness that serve mainly to regulate and legitimize what is produced and offered.

Palabras Clave: Realidad, objetividad, retórica periodística, veracidad.

Key Words: Reality, objectivity, journalistic rhetoric, truth

\section{Introducción}

"La norma de veracidad que obliga a cualquiera que haga discursos sobre la realidad y que, además, pretenda que se considere tales discursos como decidores de lo que la realidad efectivamente es, significa para el periodismo una obligación adicional" (Gomes, 2009, p4.)

De este modo, para efectivarse como un discurso de la verdad, el periodismo emplea estrategias para intentar persuadir a su público y hacerle creer que aquello que le es contado es el relato fiel de la realidad y no una construcción narrativa. Es en este sentido que se constituye la ilusión tan cara para esta práctica, en la cual hay una defensa de una supuesta capacidad de traer, bajo la forma de noticia, el hecho en sí, como si ello representara un bloque de realidad externo e inmune a la acción de narrar. Este tipo de concepción es frecuentemente encontrado en manuales de periodismo, (TRAVANCAS, 1992; BARBEIRO E LIMA 2002; PATERNOSTRO, 1987; CARDET E SILVA, 1984; entre otros), principios editoriales, (CLARÍN, 1997; ORGANIZAÇÕES GLOBO, 2011; FOLHA DE S. PAULO, 2010; LA VOZ DEL INTERIOR, 1990, 2006; entre otros) y en muchas teorías que defienden la creación de una deontología periodística; y/o la existencia de criterios fijos y pertinentes para la "aprehensión" de la realidad y su "presentación" como relato. (BELTRÃO, 1969; MELO, 2004, 1994; ERBOLATO, 1988; LAGE, 2002, 2005; entre otros). 
Muchas veces, tales discusiones abordan el periodismo a través del prisma profesional, interesadas en promover la figura del periodista como actor privilegiado (si no el único) en el proceso de "transposición" de la realidad. La base especular que sostiene este argumento postula que la noticia funcionaría como una especie de duplicación de fragmentos de un real preexistente. Algo sucede en el mundo y el profesional de la información está allí para ir y cosechar la realidad objetivamente, apropiándose de instrumentos que le garantizarían pluralidad e independencia (como sería el recurso de ceder la palabra a varios lados de una disputa, el uso de datos científicos, la consulta a fuentes fiables etc.). El texto periodístico, poco problematizado, sería, por lo tanto, caracterizado por una denotación transparente y su sentido totalizable e inmanente.

Dicha visión parece problemática y reductora en la medida en que plantea la existencia de un "modo de ser ideal del periodismo" que, además de no coincidir con lo que es producido y ofertado ni siquiera en una matriz realista, parece excluir inclusive experiencias periodísticas diversas que están más allá de cualquier recetario. De hecho, ¿cómo comprender desde esta perspectiva un João do Rio, Rodolfo Walsh, Euclides da Cunha, Roberto Arlt, David Nasser, Nelson Rodrigues y los diversos libros de cronistas? ¿O todavía la constitución y circulación de innumerables revistas que, pretensiosamente, huyen al ritual estratégico de la objetividad, como son ejemplos: la brasilera Piauí, la peruana Etiqueta Negra, o la hispanoargentina Orsai? ¿En suma, podemos considerar como única y uniforme las diversas narrativas que componen la topografía de un mismo diario, en sus diferentes secciones, columnistas, estilos etc.?

Es justamente en este sentido que, en efecto, preguntamos: ¿Cómo debemos proceder, entonces, con una revista que asume esa paradoja del discurso periodístico como su punto de partida y de actuación al advertir ya desde su tapa que "no toda la información [allí] publicada ha sido debidamente chequeada"? ¿Cuáles son las implicaciones y tensionamientos que son ofrecidos y cómo ellos nos ayudan a comprender mejor las dinámicas del periodismo contemporáneo? El objetivo de este trabajo es, pues, investigar 
narrativas del periódico argentino Barcelona, buscando comprenderlas como gestos críticos problematizadores de algunos conceptos reguladores del periodismo.

Dicha publicación, como veremos, parece problematizar desde el interior del mismo periodismo al desplazar una serie de convenciones, apuntando dimensiones conflictivas y espacios de indefinición existentes en las narrativas periodísticas. Además, sugiere que los procedimientos que utiliza de manera notoriamente ficcional no son tan diferentes de aquellos manejados por el periodismo de referencia, lo que nos conduce a una problemática interesante. Esto porque sus narrativas parecen indicar que las fisuras en el espejo realista están presentes en cualquier producción periodística y, en este sentido, Barcelona es capaz de alcanzar críticamente toda una epistemología del periodismo. En definitiva, lo que la publicación provoca, tal vez, sea semejante a la pregunta propuesta por Carvalho (2012) cuando indaga: "¿en qué medida las teorías que buscan comprender el periodismo estarían operando conceptualmente a partir de las propias dicotomías y simplificaciones típicas de los procesos de producción de las noticias?" (CARVALHO, 2012, p.18). Es en dirección a un cuestionamiento de esas dicotomías y simplificaciones que la narratividad crítica de Barcelona, como veremos, parece conducirnos.

\section{Antecedentes}

\section{Una solución europea a los problemas de los argentinos: Barcelona}

En abril del 2003, apareció por primera vez en los puestos de diarios argentinos una publicación cuya disposición verbovisual remitía a la diagramación de los principales periódicos de este país, pero con titulares difíciles de ser pensados para el periodismo de referencia, entre ellos, "La Argentina se estaría yendo a la mierda " o "Vuelven los culos grandes". Además, el periódico traía en su interior notas que abordaban la realidad social y los regímenes de poder instituidos de una manera sarcástica e irónica, sugiriendo una serie de desplazamiento en la mirada. $Y$ todo esto con un tipo de estructura que se acerca a lo que 
sería "típicamente periodístico", pero con narrativas visiblemente ficcionalizadas, escapando y, a la vez, tensionando una pretendida objetividad.

Los orígenes de Barcelona se remontan a una Argentina en plena crisis del comienzo de los años 2000. En el momento más crítico del país, la pobreza llegó a 57\% de la población, con una tasa de desocupación superior a 20\%. Cacerolazos y protestas eran frecuentes y el sentimiento de sospecha era general en relación a las principales instituciones: en un período de menos de un mes, asumieron cinco presidentes. En los bancos, la caja de ahorro estaba confiscada. La prensa también era blanco de críticas. En los muros, era común leer el grafiti que decía "Nos mean y los medios dicen que llueve". En ese escenario de crisis institucional, un grito se había vuelto slogan en los cacerolazos: "Qué se vayan todos".

En un contexto social y económico caótico, pequeños medios de comunicación y periodistas no salieran incólumes. En ese período, la mayoría de los socios-fundadores de Barcelona trabajaba en La García, cuyos reportajes eran escritos con un fuerte tono humorístico. En el 2001, sin embargo, la publicación cierra sus puertas y el grupo de amigos desempleados intenta poner en marcha el proyecto de seguir trabajando juntos y de hacer una revista política, que venían gestando desde el año 2000. Según Ingrid Beck, editora-jefe del periódico,

[e]ncontramos en el formato de Barcelona una forma de hacer periodismo sin tener que trabajar demasiado, o sea, sin tener que salir a la calle, hacer investigación o chequear ningún dato y aún así seguir siendo periodismo. Nos juntábamos a leer Clarín y La Nación y, entre risas e indignación, apareció como interesante la idea de hacer una crítica a los medios de comunicación desde la parodia. (Entrevista concedida en 16 de abril de 2012)

Oriunda de la descreencia de la crisis, Barcelona asume, desde su comienzo, una posición de no adhesión a las "grandes verdades del mundo" y satiriza los más variados discursos. Se burla de la sociedad argentina, de sus sindicatos, políticos y los más diversos actores sociales. Muchas veces lo hace con un fuerte tono político y ácido capaz de provocar una gran incomodidad. Como plantea Carlón (2006, p.4), "Barcelona molesta, incomoda. Cuando 
no ofende, produce risa y escándalo. Y enseguida un sentimiento parecido a la culpa, porque no está bien reírse de los temas que Barcelona trata, como los trata Barcelona". Por afrontar la estética realista típica del periodismo, frecuentemente Barcelona es presentada o asociada a "revistas de humor", lo que sus editores rechazan vehementemente. Ingrid Beck, al contestar sobre el tema, afirma categóricamente que "cuando Clarín sea considerado humorístico quizá acepte este rótulo a la Barcelona, pero lo que nos esforzamos para hacer es periodismo. La risa es un efecto, una consecuencia". Lo que se nos plantea ahí es, por lo tanto, la puesta en disputa de la propia definición de lo que sería periodismo, de sus contornos, características y límites.

\section{Discusión}

\section{La narratividad crítica}

Barcelona no adhiere a un cierto discurso periodístico y, como producto mediático, propone narrativas que rompen la ilusión referencial a partir de la despragmatización de las unidades informativas. Eso se da en toda su extensión (tapa, contratapa, publicidad, fotos, notas etc.). Sin embargo, para los fines de este trabajo, nos detendremos en la unidad informativa "nombre del periódico" y en el análisis de una noticia².

La tapa de una publicación es el primer ambiente de contacto entre lectores y el sujeto semiótico "periódico". Por eso, representa un importante elemento de persuasión, actuando como una especie de anticipo del contenido traído por los diarios y revistas, y también como una dicción o posicionamientos específicos de cada sujeto semiótico. (Leal, 2006; Landowski, 1992; Moura, 2010). Funciona así, como un lugar de ubicación para el lector y como espacio de anclaje y de jerarquización temática. En la tapa, aunque las noticias se renueven en cada número hay algo que siempre se repite para garantizar unidad e isotopía:

\footnotetext{
${ }^{2}$ Un análisis más detallado de la narratividad crítica de Barcelona fue realizada en nuestra disertación de maestría (ver Jácome, 2013).
} 
se trata del nombre del periódico. Como plantea Mouillaud (2002, p.88), el nombre sirve como una firma y "se refiere a un doble paradigma; en el espacio se remite a los diarios que son su competencia; en el tiempo, a los otros números de la colección". El "nombre del periódico" representa, así, un modo de enunciación particular que diferencia cada sujeto semiótico, en la misma medida en que funciona como una especie de abrochadora para los demás títulos contenidos en su edición.

La mayoría de las veces, la unidad informativa "nombre del periódico" conlleva informaciones bastante similares en los variados medios. Está casi siempre ubicada en la parte superior de la página, con gran destaque visual, preparando los enunciados que seguirán abajo, bajo su tutela. En la Folha de S. Paulo, por ejemplo, podemos percibir el nombre del periódico escrito con una fuente sobria, en mayúscula sostenida. Debajo de éste, aparece su lema destacado con color rojo y precedido por tres estrellas (con los mismos colores de la bandera del estado de San Pablo): "un diario a servicio de Brasil". El slogan marca el compromiso del periódico y lo ofrece como un servidor de la comunidad del que es parte, generando una camada de significación al nombre que se expone.

Unidades informativas semejantes son encontradas en otros diarios de referencia como $O$ Globo, La Nación, Página/12, El Mercúrio etc. En todos, el "nombre del periódico" es marcado por un tono serio e institucional, por el que el sujeto semiótico se ofrece como "creíble", "responsable", "imparcial" y propone un primer acuerdo de confianza con su público, como podemos observar también en The New York Times:

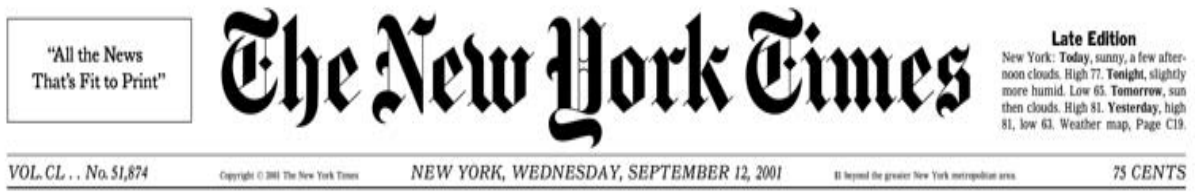

Fuente: Edición $n^{\circ} 51.874$ 
Del lado izquierdo al nombre del periódico, notamos un rectángulo con la frase "Todas las Noticias Aptas a ser Impresas". Con ella, el sujeto semiótico ofrece a sus lectores y anunciantes el compromiso de que su contenido fue blanco de una selección criteriosa, digno de ser publicado y que puede, entonces, ser digno de confianza y credibilidad. Podemos, así, decir que el módulo "nombre del periódico" se superpone a las demás unidades informativas, que pasan a ser subordinadas a él. Muchas veces, los sujetos semióticos asumen ese compromiso con el lector a través de slogans como "un periódico al servicio de Brasil", "el gran periódico de los mineros" (Estado de Minas), entre otros. Clarín, en este sentido, no es una excepción:

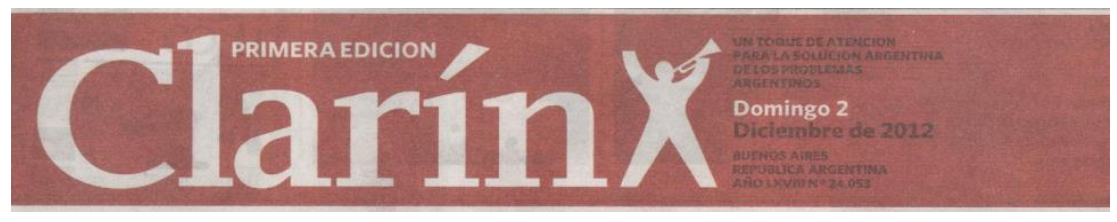

Fuente: Edición n²4.053 de Clarín

La marca es construida y dispuesta para connotar el sentido de "vigilante" de los acontecimientos, si se tiene en vista que el clarín -como instrumento musical- es históricamente asociado a los "avisos", a la "señalización". Tal idea es reforzada todavía más por el lema del periódico, localizado en frente del clarín de la silueta, dando la impresión de que proviene de ella. Es como si la figura hiciera sonar: "un toque de atención para la solución argentina de los problemas de los argentinos".

El periódico, por lo tanto, se coloca como un centinela de la realidad argentina. Más abajo, percibimos además otros elementos que complementan y marcan estas nociones de comunidad y de que la sociedad a partir y para la cual el periódico habla es la misma que la de su público ("Buenos Aires - República Argentina"). De este modo, el "nombre del periódico" funciona también como una referencia espacial de anclaje para todos los otros 
enunciados del periódico. Es él el que da unidad a los otros fragmentos y los reúne en una misma escena enunciativa, generando un sentido de pertenencia a una comunidad que comparte, en el momento de lectura, un mismo mundo y un mismo tiempo.

En Barcelona, por su parte, podemos percibir un primer gesto crítico ya en el nombre de la publicación, por ejemplo, cuando retoma (a través de una inversión de valores) los "ideales" de Clarín:

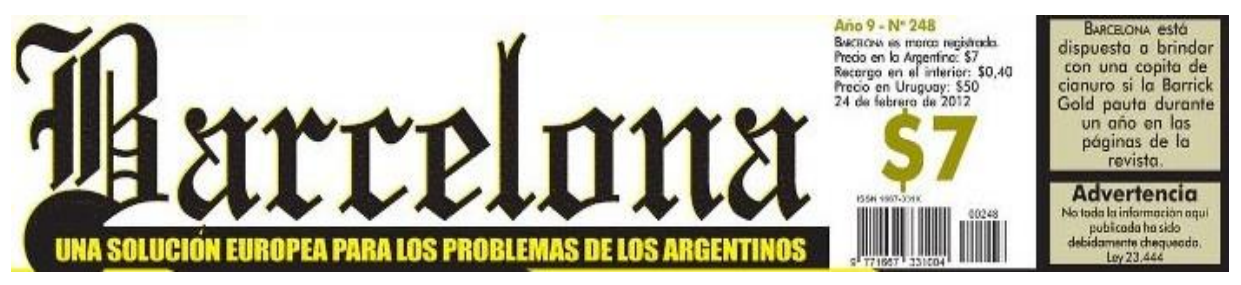

Fuente: $N^{\circ} 248$ de Barcelona

El slogan de la revista remite claramente al del diario porteño al resaltar "una solución europea para los problemas de los argentinos". Se produce ahí un tensionamiento tanto en la relación con Clarín, como con los presupuestos periodísticos más generales de un periódico capaz de retratar la realidad de una comunidad específica. Como podemos percibir en los ejemplos de arriba, muchos periódicos refuerzan la noción de pertenencia nacional o local y se colocan como guardianes de la sociedad de la que son parte. El propio nombre de las publicaciones representa un índice de esa movilización identitaria, y rescata aspectos ideológicos, históricos, etc. No casualmente varias denominaciones son: "La Voz Del interior", "Jornal do Brasil”, "The Washigton Post". El "nombre del periódico" en Barcelona, sin embargo, quiebra con esa expectativa, ya que representaría no una "voz" local, retratando una realidad común o "resolviendo" los problemas que son de aquella comunidad. Por el contrario, se trataría de una solución externa, europea. Recordemos que la publicación comienza a ser gestada durante la crisis argentina de los años 2000, momento en el que el 
país sufría con intervenciones del FMI, después de una década de gobiernos neoliberales y que muchas personas estaban migrando para otros países (siendo España uno de los predilectos y la ciudad de Barcelona, vislumbrada como uno de los principales destinos). En este gesto, el periódico rompe también con la idea de que el periódico debe "estar al servicio de la nación" o representar "un toque de atención".

Seguidamente, la revista trata de enturbiar la idea de periodista como una fuente creíble, en la medida en que invierte los ideales de imparcialidad y de capacidad para retratar fielmente una realidad. Percibimos, además, que el "nombre del periódico" de la publicación argentina retoma críticamente el $N Y T$ (la fuente utilizada en una y en otra es la misma). Esto porque posteriormente, en la tapa, hay una advertencia que, aunque visualmente sea parecida a la del periódico estadounidense, posee un contenido muy diferente. En el rectángulo a la derecha, leemos: "No toda información ha sido debidamente chequeada". La credibilidad, que parece ser un factor determinante para el pacto de confianza entre lectores y medios noticiosos, es puesta en jaque, por lo tanto, inmediatamente en la tapa de Barcelona. En este sentido, si el módulo "nombre del periódico" es responsable por los demás enunciados, todas las otras narrativas de la revista pasan a estar bajo sospecha, ancladas en conjeturas ambiguas. Al colocar "no toda", la revista afirma que algunas informaciones no fueron debidamente chequeadas, al mismo tiempo en que no asegura que otras puedan haberlo sido. En el aviso, no obstante, podemos observar la estrategia de proposición de una duda que parece insoluble.

El periódico rechaza el dogmatismo moral en la misma medida en que utiliza algunas estrategias textuales típicas. Su "advertencia" es seguida de la "Ley 23.444", lo que representa, desde nuestra perspectiva, un gesto de desestabilización del uso de estas unidades informativas. Esto porque una primera lectura sugiere que la falta de chequeo de la información podría ser amparada por dicha ley. Dado que, siguiendo la memoria de cómo llevar a cabo la lectura, una ley colocada como salvaguarda de una información debe autenticarla de alguna manera. Una sorpresa es causada al saber que la ley a la cual se 
refiere Barcelona hace referencia a una legislación que regula la difusión de la publicidad de cigarrillos en la radio y la televisión, y que no guarda, por ende, ninguna ligación explícita con la advertencia expuesta por la revista. La relación es dada por el propio gesto narrativo que conecta la idea de ley a la autenticación de la realidad, ya que ella, convencionalmente, funciona como un discurso de autoridad que restringe, permite, confirma, etc. Más allá de esto, la idea de ley puede ser interpretada como una especie de norma a ser seguida, un deber a ser cumplido. En el caso del periodismo, los profesionales tienen como "obligación" decir la verdad, chequear y verificar la realidad. Esto parecería ser fundamental para la creación de la imagen de una enunciador legítimo capaz de traer los hechos del mundo para sus páginas. Barcelona pone en jaque su propia fiabilidad, pero al remitir directa o indirectamente a otros vehículos y al apropiarse de un cierto modo de realización periodística, ella también tensiona algunos discursos legitimadores del periodismo. Este tipo de estrategia sobrepasa la construcción de sus noticias y se revela como una marca de su narratividad. Ejemplo de esto es una nota del ํㅜ 239 que refiere a una entrega de casas sin baño a la comunidad Wichi por el gobierno de Salta: 


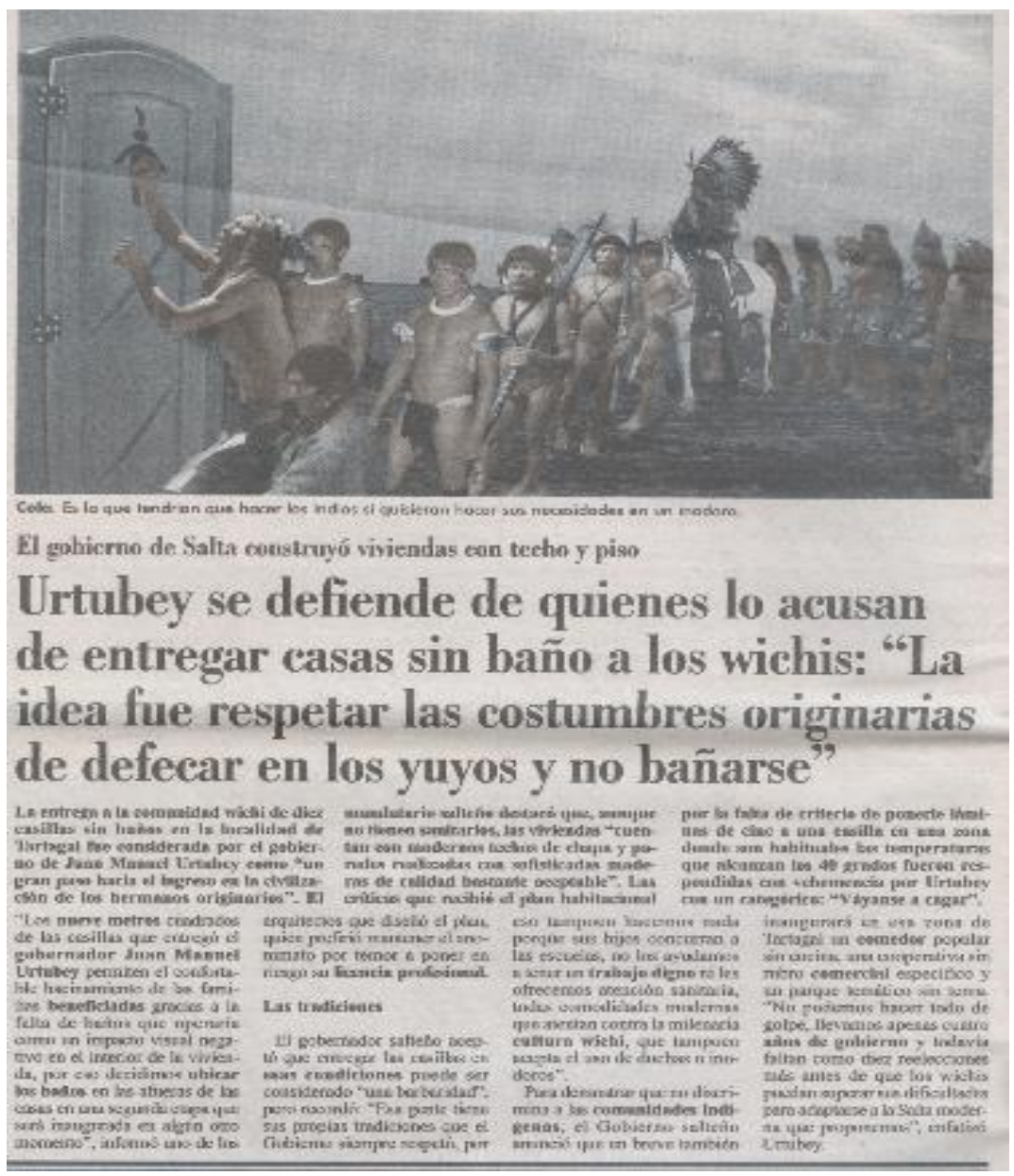

En el título de la nota, ya podemos percibir la construcción peculiar que Barcelona realiza para las citaciones, retratando lo que habría dicho el gobernador de aquella provincia: "Urtubey se defiende de quienes lo acusan de entregar casas sin baño a los wichis: 'La idea fue respetar las costumbres originarias de defecar con los yuyos y no bañarse'" (el destacado es nuestro). En dicho enunciado, atribuido a Urtubey, podemos observar una justificación construida a partir de un desconocimiento peyorativo en relación a las que serían las "costumbres indígenas". Esa carga de prejuicio, sin embargo, es atribuida ficcionalmente al discurso del propio gobernador y surge para contestar, en el plano de referencia, su acción "real". Tales dichos son además contrapuestos por una inversión de sentidos sugerida por la obviedad de la volanta: "El gobierno de Salta construyó viviendas con techo y piso". O sea, a 
través de la redundancia, la publicación explicita aquello que es evidente (una casa posee techo y piso), para resaltar y evaluar críticamente lo insólito que correspondería a una casa sin baño, relacionándola a los dichos apócrifos del gobernador. En el subtítulo, ese juego de valoraciones disonaste continúa:

La entrega a la comunidad wichi de diez casillas sin baños en la localidad de Tartagal fue considerada por el gobierno de Juan Manuel Urtubey como "un gran paso hacia el ingreso en la civilización de los hermanos originarios". El mandatario salteño destacó que, aunque no tiene sanitarios, las viviendas "cuentan con modernos techos de chapa y paredes realizadas con sofisticadas maderas de calidad bastante aceptable".

En ese pasaje, podemos percibir un proceso semántico en el cual los referentes son combinados y caracterizados por adjetivos contradictorios, lo que resalta la evaluación cuestionadora de Barcelona: casas de chapa "modernas", construidas con maderas "sofisticadas", de calidad "bastante aceptable". Lo interesante de la construcción narrativa del periódico es que ella crea, por lo menos, dos planos de enunciación, movilizando elementos de la referencialidad para producir nuevas relaciones de sentido. Al dar crédito a los dichos del gobernador, ella demuestra no lo que él dijo, pero sí la punzante actitud evaluadora de Barcelona acerca de aquello que él hizo. En el fragmento, la revista sienta sus bases referenciales (las casas fueron entregadas en esas condiciones), al mismo tiempo que utiliza su construcción narrativa para subvertir valores y deslegitimar la acción del político. La desproporcionalidad de las frases, construidas a partir de una estructura típicamente periodística, propone una complicidad con el lector, capaz de reconocer que es una aseveración inventada, pero que produce una crítica verdadera. Lo que la Barcelona hace es, en este sentido, retomar críticamente el mundo referencial exacerbando su carácter de absurdo y articulando contradicciones en una estructura inclusiva, capaz de soportar varias camadas de significación. Todo eso para tejer su plan argumentativo cuestionador. 
Como podemos notar, hay una aparente "transferencia de enunciación" con la utilización de comillas que marcarían la diferencia entre el enunciado del periódico y la cita perteneciente a fuentes autorizadas. Sin embargo, la publicación propone la ruptura de la ilusión de la "reproducción", a través de la hipérbole, de la paradoja, de construcciones textuales disonantes. En ese sentido, Barcelona posee un carácter extremamente ambiguo como periódico: desplaza convenciones de otros diarios y simultáneamente las afirma en la construcción de su propia identidad. Es que necesita de las realidades configuradas por otros medios de comunicación para combinarlas con su actitud evaluadora y crítica. En esta empresa, el periódico emula procedimientos que podríamos considerar como "generales" al periodismo. En este gesto, propone una discusión autorreferencial, llamando la atención sobre el texto y el carácter convencional de ciertas estructuras narrativas. Por esto, su narratividad puede ser considerada como "metaperiodística" o "metaficcional".

Como apunta Bernardo (2010), la metaficción es un fenómeno estético en la que, por definición, la obra se dobla y desdobla dentro de sí. Como consecuencia, esa multiplicación interna de esas marcas de ficcionalidad se opone a la demanda realista que postula que el lenguaje representa la realidad. Según el autor, la metaficción

desconfía de la realidad, luego desconfía del realismo. La metaficción desconfía del autor, luego desconfía también del lector. La metaficción desconfía de sí misma, ella se pone al borde de un abismo. La metaficción representa, así, la búsqueda de la identidad, pero al mismo tiempo define esa búsqueda como agónica. (BERNARDO, 2010, p.52. Traducción nuestra)

¿Y no es justamente eso lo que podemos percibir en Barcelona? ¿Sus narrativas no proponen una desconfianza que quiebran con una idea especular de periodismo? Al desconfiar de los usos de las unidades informativas y proponer nuevos arreglos a "lo real" que configura, Barcelona enturbia la ilusión referencial, sugiriendo que sus narrativas 
funcionan como una máscara metafórica. Pero no sólo eso. Al remitir a los otros periódicos, apropiándose de sus procedimientos, la publicación argentina enfrenta a todo un discurso periodístico basado en una relación epistemológica con la realidad. Y lo hace exigiendo que estemos atentos a los procesos de configuración ésta que se volvieron posibles por la propia narrativa, lo cual parece bastante provocador.

Es que el realismo periodístico parece significar un intento de adecuar la escritura a un solo plan de experiencia temporal posible, cuyos límites estarían confinados a su propia historicidad. En este sentido, una reflexión sobre la narrativa tiende a ser desconsiderada, en la medida en que ésta funcionaría solamente como un "vehículo", o sea, como un artefacto para transmisión de la información clara y concisa al espectador. Se percibe ahí, que verdad y realidad estarían ajenas a los procesos de narrativización, en la medida en que el mundo "transportado" por el texto periodístico correspondería o, por lo menos, debería correponder a un mundo de referencia fijo, sin, por lo tanto, ningún embate entre el mundo del texto y el mundo del lector.

Esta concepción de la narrativa, sin embargo, nos parece deficitaria, teniendo en cuenta que desconsidera el cambio comunicacional inherente a cualquier proceso de producción de sentidos. Esto porque se plantea que no habría distancia entre la narrativa tejida y el mundo que existe más allá de ella, en la medida que la "verdad" y la "realidad" de un texto solo serían consecuencias naturales del esfuerzo de un buen chequeo de datos. De este modo, la lectura sería fortuita y no interferiría en aquel texto producido, ya que delante de un bloque de lo real inmóvil, cualquier esfuerzo de interpretación parece sonar inútil y desnecesario. Dicha concepción genera una identidad específica para el periodismo, pero también las posibilidades de eclosión de las contradicciones múltiples que lo constituyen.

Y esto está, como vimos, en el núcleo de la narratividad crítica de Barcelona, en la medida en que la publicación explicita una serie de convenciones en su auto-reflexión periodística. La publicación no ofrece un auto-desnudamiento que revela y resalta la "ficcionalidades", es decir", el acto configurante, o el "poner-en-trama" (Ricoeur). Y lo hace accionando las propias 
narrativas y el formato periodístico sedimentados, volviéndolos opacos a partir de los mismos elementos que generarían la transparencia. De este modo, al emplear y criticar los propios métodos de construcción periodísticos, las composiciones de Barcelona cuestionan límites y presuposiciones rígidas, proponiendo nuevas formas de acceso y de configuración de la realidad.

Aunque utilice comillas apócrifas, construya periodistas y narradores que generan desconfianza o presente acontecimientos aparentemente inexistentes, ella no lo hace para engañar a su lector. Al contrario, le revela su gesta evaluadora y, por eso, su ficcionalidad es utilizada para promover una relación en la que el lenguaje se muestra a sí mismo como una creación, al mismo tiempo en que la revista aprecia este poder de innovación semántica. Así, las narrativas de Barcelona no esconden lo que son: una construcción en el lenguaje y no un relato "puro" de una sola verdad posible. En este sentido, ella confunde y cuestiona el "aura de autoridad" de los otros periódicos desde su propia variación imaginativa, de su "poner-entrama".

\section{Conclusiones}

En suma, se demuestra que la "verdad", valor tan caro y necesario, del cual el periodismo parece no poder desvincularse, es algo mucho más complejo que una serie de códigos o de principios morales. A través del metaperiodismo, ella trabaja las fisuras del discurso que se pretende objetivo y totalizador, "dueño" de una supuesta realidad fija. Su gesto autorreferente nos interpela a buscar otras soluciones para el periodismo, para que lo entendamos mejor, su referencialidad, su relación con la ficcionalidad y, principalmente su característica decididamente comunicacional.

Gestos como los de Barcelona corroboran para que alejemos la noción de periodismo como un único modo de ser. En definitiva, al mirar atentamente a las narrativas, percibimos que ellas se ofrecen como un lugar de intersección entre el mundo del texto y del lector. Mundos estos bastante diversos. Por ende, acreditamos que comprender los fenómenos periodísticos 
por el prisma narrativo, quizás nos permita avanzar en su entendimiento, accionando criterios menos rígidos. Esto es, el amparo narrativo deja entrever la existencia de variados agentes, y el periódico pasa a ser un lugar de experiencia, de propuesta de una configuración de lo real que no puede solaparlo ni abarcarlo por completo.

\section{Bibliografía}

ABRIL, Gonzalo. (2007) Análises crítico de textos visuales. Madrid: Síntesis.

BARBEIRO, H.; LIMA, P. R. (2002) Manual de telejornalismo: os segredos da notícia na TV. Rio de Janeiro: Campus.

BARTHES, Roland. (2004) O efeito de real. In: O rumor da língua. Trad. Mário Laranjeira. São Paulo: Cultrix.

BELTRÃO, L. (1969) Iniciação à filosofia do jornalismo. Rio de Janeiro: Agir.

CARLÓN, Mario; "Y al final... ¿qué hacemos con Barcelona?”; Revista La Crujía; Buenos Aires, octubre de 2006.

CARVALHO, Carlos Alberto de ; BRUCK, Mozahir Salomão (2012). Jornalismo: cenários e encenações. 1. ed. São Paulo: Intermeios - Casa de Artes e Livros.

CARVALHO, Carlos Alberto de ; LEAL, Bruno Souza. (2012) Jornalismo e homofobia: mapeamentos e reflexões. 1. ed. São Paulo: Intermeios Casa de artes e livros.

CLARÍN.(1997) Manual de estilo. Buenos Aires: Clarín Aguilar.

DAVIS, Lennard J. (1983) Factual Fictions: the Origins of the English Novel. Nova York. Columbia University Press..

ECO, Umberto (1986). Lector in fabula. São Paulo: Perspectiva.

ERBOLATO, Mario L. (1982). Deontologia da comunicação social. Petropolis: Vozes. 
FOLHA DE S. PAULO (JORNAL). Novo manual da redação. (1993). 2. ed. São Paulo: Folha de S. Paulo.

FONTCUBERTA, Mar de. (2003) La noticia: pistas para percibir el mundo. Barcelona: Paidós.

GOMES, Wilson. (2009) Jornalismo, fatos e interesses: ensaios de teoria do jornalismo. Florianópolis: Insular

HUTCHEON, Linda; PÉREZ, Teresa Louro (1989). Uma teoria da paródia: ensinamentos das formas de arte do Século XX. Lisboa: Ed. 70.

HUTCHEON, Linda; JEHA, Júlio. (2000) Teoria e política da ironia. Belo Horizonte: Editora UFMG.

JÁCOME, Phellipy Pereira. (2013). Fissuras no espelho realista do jornalismo: a narratividade crítica de Barcelona. Dissertação de mestrado. Faculdade de Filosofia e Ciências Humanas. Universidade Federal de Minas Gerais.

LAGE, Nilson. (2002) Linguagem jornalística. $7^{\text {a }}$ Edição. São Paulo: Ática.

LEAL, Bruno Souza.(2006) Saber das narrativas: narrar. In: Vera França; César Guimarães. (Org.). Na mídia, na rua: narrativas do cotidiano. 1 ed. Belo Horizonte: Editora Autêntica, p. 19-28.

LEAL, Bruno Souza (2002). A produção da familiaridade e o pacto de leitura jornalístico. Salvador: Intercom.

LEAL, Bruno Souza; JÁCOME, Phellipy (2011). Mundos possíveis entre a ficção e a "nãoficção": aproximações à realidade televisiva. Porto Alegre: Famecos.

LEAL, Bruno Souza; JÁCOME, Phellipy. (2012) Outros agentes na comunidade interpretativa do jornalismo. Anais do $10^{\circ}$ Encontro Nacional dos Pesquisadores em Jornalismo, SBPJOR: Curitiba. 
MOUILLAUD, Maurice (2002). O nome do jornal. In: PORTO, Sérgio Dayrell (Org.). O jornal: da forma ao sentido. Trad. Sérgio Gossi Porto. Brasília: UnB

MOURA, Maria Betânia (2010). Por uma teoria do formato jornalístico: reflexões sobre o jornal como sujeito semiótico. Belo Horizonte: Tese de doutoramento.

RICOEUR, Paul. (1994). Tempo e narrativa. Tomo I. Campinas: Papirus.

RICOEUR, Paul. (1995). Tempo e narrativa. Tomo II. Campinas: Papirus.

RICOEUR, Paul (1997). Tempo e narrativa. Tomo III. Campinas: Papirus.

TRAQUINA, Nelson. (2001) O Estudo do Jornalismo no Século XX, São Leopoldo (Brasil), Editora Unisinos.

\section{Forma de citar este artículo en bibliografías}

JÁCOME, P. (2013): "La narratividad crítica de la revista Barcelona", en Revista PANGEA, 4, páginas 289 a 306. Red Académica Iberoamericana de Comunicación. Recuperado el de de 2 de: http://revistapangea.org 